Classification

Physics Abstracts

$07.80-82.80$

\title{
Report on the 1993 and 1994 Round Robin EDXS Tests of the Ile de France TEM Network $\left({ }^{\star}\right)$
}

\author{
Danièle Bouchet $\left({ }^{1}\right)$ and Jannick Ingrin $\left({ }^{2}\right)$
}

( $\left.{ }^{1}\right)$ Laboratoire de Physique des Solides, UA 002, Bât. 510, Université Paris-Sud, 91405 Orsay, France

(2) Laboratoire de Géophysique et Géodynamique Interne, URA 1369, Bât. 510, Université ParisSud, 91405 Orsay, France

(Received June 9; accepted June 16, 1995)

Résumé . - Comme en 1992, le "Réseau Francilien de Microscopie Electronique en Transmission" a animé en 1993 et en 1994 un atelier de recherche régional intitulé "Analyse Chimique" dont l'activité essentielle consiste à organiser des tests tournants. Le but de ce court rapport est de mettre en lumière l'intérêt de ces tests collectifs pour l'acquisition de procédures de travail rigoureuses. La maîtrise de l'analyse quantitative d'échantillons homogènes est considérée comme une condition absolue pour la réalisation d'analyses beaucoup plus complexes telles que celles de nanohétérogénéités.

\begin{abstract}
As in 1992, the "Réseau Francilien de Microscopie Electronique en Transmission" has run in 1993 and 1994 a regional research workshop entitled "Chemical Analysis", with main activity being, up to now, to organize round robin tests. The purpose of this short report is to demonstrate the interest of these round robin tests for the set up of rigorous working procedures, assuming that this mastery is an absolute condition to perform much more complex experiments such as quantitative analysis of nanoheterogeneities.
\end{abstract}

\section{Introduction}

Since 1992, the "Francilian TEM Network" organizes every year a round robin test on TEM microanalysis within a research workshop entitled "Chemical Analysis". Let's recall the principle of these tests: the same specimen circulates among microscopists participants who are supposed to

$\left.{ }^{\star}{ }^{\star}\right)$ D. Bouchet (LPS/CNRS, UPS Orsay); J. Ingrin (Géophysique et Géodynamique Interne , CNRS, UPS Orsay); D. Imhoff, C. Marhic (LPM-CNRS Meudon); F. Glas (CNET Bagneux); C. Haut (LMS-CNRSUPS Orsay); P. Dascotte, E. Merlen (IFP Rueil-Malmaison); P. Galtier, M. Magis (Thomson-CSF Orsay); L. Beylat (CREA- ETCA Arcueil); J. Devaud, J.L. Pastol (CECM-CNRS Vitry); R. Molins (EMP Paris); Y. Wang (LMC Paris VI); M. Capelle, J.C. Ménétrier (PSA-Peugeot-Citroën Vélizy-Villacoublay); Y. Montardi (Rhône Poulenc-CRA Aubervilliers); L. Boulanger (CEA Saclay). 
find its composition. The results are gathered and analysed by the animators. All the problems encountered during the analysis are then discussed between all the participants.

The improvements of energy dispersive X-ray spectroscopy (EDXS) attached to TEM require more and more careful, rigorous measurements performed with highest precision. The great interest of such a kind of both solitary and collective work is the opportunity for the microscopists to improve by themselves their practical ability and to share their experience with others without any kind of competitiveness. The ultimate aim is to optimize and to harmonize the quantitative analysis procedures.

The subject of the 1992 test was "the determination of the quantitative composition of an homogeneous Olivine San Carlos thin foil" and has already been reported [1]. Two main conclusions of this test concerned the utilization of $k$-factors and the application of absorption corrections. We have decided to slightly change the direction of the test in order to emphasize the pedagogical aspect of the analysis especially on these points. We report here the results together with a critical evaluation of the 1993 and 1994 tests which were respectively dedicated to the experimental determination of $k$-factors and the analysis of light elements.

Fourteen laboratories affiliated to CNRS, Universities, or Industries and near 30 francilian microscopists have been involved in this research workshop.

The detailed description of the different microscopes involved in the test can be found in [1].

\section{Test 1993: "Determination of the Fe/Si $k$-Factor and Application to an Homogeneous Unknown Sample"}

2.1 TEST CONDITIONS AND RESUlTS - Two thin foils, both prepared by ion milling and carbon coated, have been sent to the participants. The first one was a single crystal of synthetic fayalite $\left(\mathrm{Fe}_{2} \mathrm{SiO}_{4}\right)$ [2] with $\mathrm{Fe} / \mathrm{Si}=2.00 \pm 0.03$. The composition of this sample is communicated to the participants in order to perform their own experimental calibration and determine their experimental $k$-factor of the $\mathrm{Fe} / \mathrm{Si}$ ratio. The second provided sample, a single crystal of hortonolite, is used to test the quality of their calibration. Its formula $( \pm 3 \sigma)$ has been determined by electron microprobe analysis:

$$
\left(\mathrm{Fe}_{1.233 \pm 0.027} \mathrm{Mg}_{0.641 \pm 0.023} \mathrm{Mn}_{0.136 \pm 0.006} \mathrm{Ca}_{0.0021 \pm 0.0013}\right) \mathrm{Si}_{0.987 \pm 0.005} \mathrm{O}_{4}
$$

$$
\mathrm{Fe} / \mathrm{Si}=1.25 \pm 0.01
$$

The composition of this sample is obviously not communicated and the choice of the analytical procedure(s) is up to the participants.

The great majority of the participants (7 laboratories) decided to use the parameterless extrap-' olation method proposed by Van Cappellen [3]: measurements of $I_{\mathrm{Fe}} / I_{\mathrm{Si}}$ at various thicknesses, plot of $I_{\mathrm{Fe}} / I_{\mathrm{Si}}$ versus $I_{\mathrm{Fe}}$, extrapolation to $I_{\mathrm{Fe}}=0$, i.e. to zero thickness. Two laboratories performed measurements in a very thin area assuming the thin film criterium is valid. Two laboratories did standard classical absorption correction, i.e. measurements of $I_{\mathrm{Fe}} / I_{\mathrm{Si}}$ at various thicknesses, thickness estimation from contamination points, evaluation of $I_{\mathrm{Fe}} / I_{\mathrm{Si}}$ at zero thickness by mean of an absorption correction formula.

Figure 1a gathers the $\mathrm{Fe} / \mathrm{Si}$ ratio results obtained by the participants for the unknown sample. The mean value, $1.22 \pm 0.16(\sigma)$ brackets correctly the true $\mathrm{Fe} / \mathrm{Si}$ ratio of the hortonolite sample with a dispersion of the results close to $13 \%$. The extreme values are 1.01 et 1.58 . 


\subsection{ANALYSIS OF RESULTS, CRITICAL EVALUATION AND CONCLUDING REMARKS}

2.2.1 Experimental versus Manufacturer Provided $k$-Factors - Most often the measured $k_{\mathrm{FeSi}}$ differ from the $k_{\mathrm{FeSi}}$ deduced from the informations given by the company. The results of this test show that the discrepancy between experimental and provided $k$-factors can reach 30 to $40 \%$ (Fig. 1b). Let's recall that the companies themselves do not guarantee the quality of their provided $k$ factors as far as good precision composition measurements are needed. The discrepancy results partly from the differences in experimental conditions between microscopists and manufacturers, the ageing of the detector system and a possible misinterpretation of the elusive information generally given by the company about their $k$-factors.

Whatever the numerous reasons for these discrepancies, the present test confirms, as far as it was necessary, the absolute necessity of experimental calibration of $k$-factors.

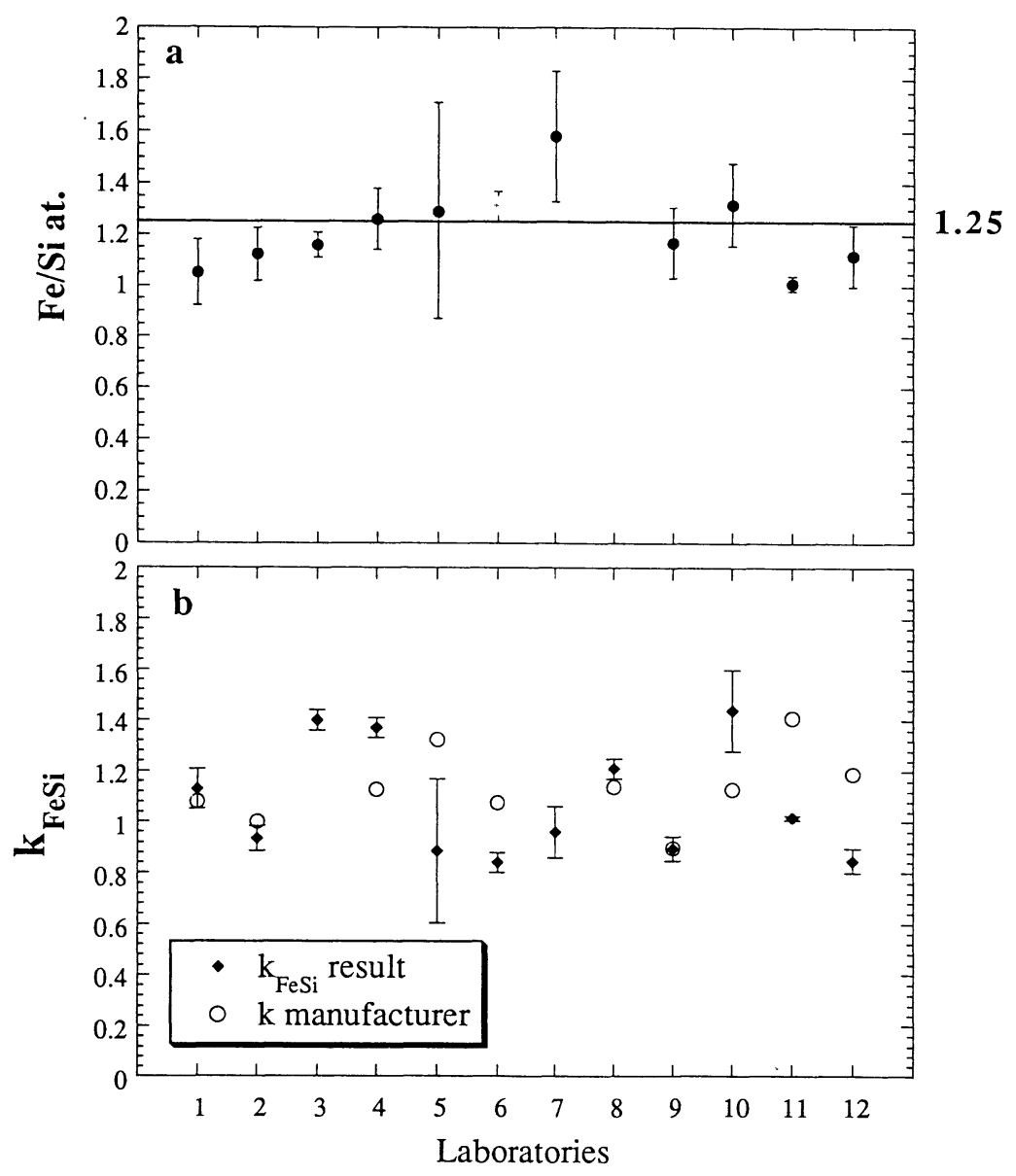

Fig. 1. - EDXS 1993 results. a) Fe/Si ratios obtained for the unknown sample. The experiments \# 1 to 7 have used the Van Cappellen method, \# 9 and 10 a classical absorption correction, \# 11 and 12 the thin film criterion. b) $k_{\mathrm{FeSi}}$ factors measured by the participants and given by their manufacturers. 
2.2.2 Compositional Changes Due to Ion Milling in Thin Areas - Van Cappellen method, which requires profile analyses from the edge towards the inner part of the foil, shows an increase of the Fe/Si ratio in the thin part of the samples (Fig. 2). This modification of composition has been quite frequently observed in alloys for ion milling and electropolishing and is generally explained by the presence on the foil surface of a thin layer which is depleted in some elements $[4,5]$. On the example reported in Figure 2, the effect of composition change becomes significant for thicknesses lower than $120 \mathrm{~nm}$ (estimation from the distance of contamination spots after tilting). We see that both ratios of peak integrals $I_{\mathrm{Si}} / I_{\mathrm{Fe}_{\mathrm{K}}}$ and $I_{\mathrm{O}} / I_{\mathrm{Fe}_{\mathrm{K}}}$ decrease significantly close to the edge of the sample while the $I_{\mathrm{Fe}_{\mathrm{L}}} / I_{\mathrm{Fe}_{\mathrm{K}}}$ is not affected by the phenomenon. This suggests that during ion milling a loss of $\mathrm{O}$ and $\mathrm{Si}$ occurred simultaneously on the surface of fayalite (resp. hortonolite). This phenomenon is still observed when ion milling is performed with liquid nitrogen cooling stage.

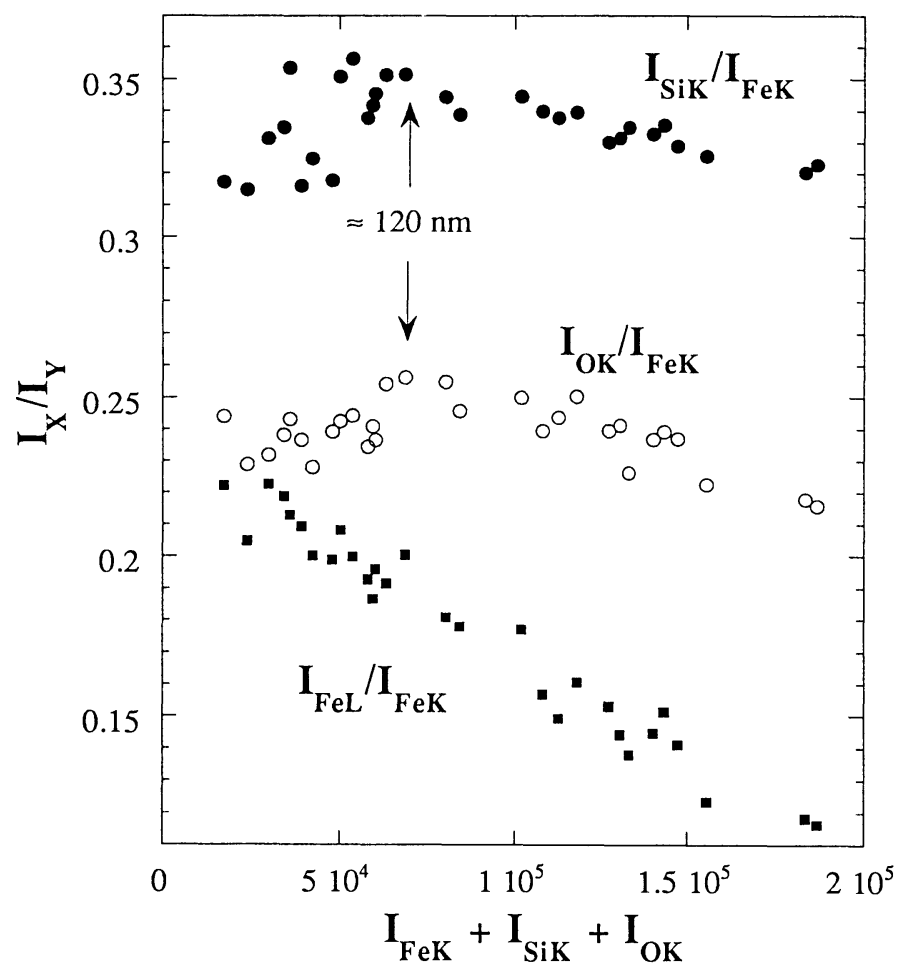

Fig. 2. - Evidence of chemical modification in a thin area from Van Cappellen method. Ratio of peak integral of two distinct elements of the fayalite sample versus the sum of peak integral of $\mathrm{Fe}_{\mathrm{K} \alpha}, \mathrm{Si}_{\mathrm{K}}$ and $\mathrm{O}_{\mathrm{K}}$. The abscissa is roughly proportional to the thickness of the sample (analyses performed at constant current intensity). Notice the loss of $\mathrm{O}$ and $\mathrm{Si}$ relative to $\mathrm{Fe}$ for the analytical points obtained on sample areas thinner than $\approx 120 \mathrm{~nm}$. The regular increase of $I_{\mathrm{Fe}_{\mathrm{L}}} / I_{\mathrm{Fe}_{\mathrm{K}}}$ for reduced thicknesses shows that the change of slope observed for $I_{\mathrm{Si}_{\mathrm{K}}} / I_{\mathrm{Fe}_{\mathrm{K}}}$ and $I_{\mathrm{O}_{\mathrm{K}}} / I_{\mathrm{Fe}_{\mathrm{K}}}$ are not due to a modification of the absorption.

As for the test results, the two measurements performed on thinner sample areas in order to get rid of the absorption correction (Labs. 11 and 12) missed this edge artifact. This partly explains the underestimations of their Fe/Si ratio values (Fig. 1a). 
2.2.3 Selection of the Best Procedure for Calibration - The thin film method used by 2 participants is not very reliable not only because of the possible composition perturbations induced by sample thinning as mentioned above, but also as a consequence of the subjectivity of the assumption of the thin film criterion validity, i.e. visual estimation of thickness range.

The classical absorption correction technique, with thickness determination from contamination spots, has been used by laboratories \# 9 and 10. This number of laboratories is too small to make any argument statistically sound. However, we have noticed that the average and the dispersion of these two values are not significantly different from the average and dispersion of the 7 values obtained by the Van Cappellen method (Labs. 1 to 7, Fig. 1a).

The quality (and homogeneity) of the results obtained by the Van Cappellen method is quite good all the more as the majority of participants were not familiar with the method. For instance, one must take care of some points: filament current should be kept constant during all the analyses, a minimum number of measurements (at least 10, condition not verified for Labs. \# 6 and 7) on a large enough range of thicknesses must be made.

As a conclusion, we believe, and this opinion is largely shared among the participants of the test, that the Van Cappellen method is the best procedure presently available for calibration of EDXS. A most important point is that the thin film artifact is only detectable by the Van Cappellen method and was effectively detected by the 7 laboratories who used it. Furthermore, contamination method for thickness measurement is well-known for leading to an overestimation of this thickness [6]. Finally, it must be quoted that contamination is generally considered as a limitation for spatially resolved quantitative chemical analysis.

2.2.4 Normalization of Uncertainties - The last remark arises from the examination of the uncertainties which have been expressed by the participants in various ways: maximum deviation, standard deviation $(\sigma)$ or not expressed at all. Consequently, starting from the detailed results, we have expressed the uncertainties of all the participants as $\sigma(\approx 68 \%$ confidence). It is thus possible to see from Figure 1 that the estimation of uncertainties varies significantly from one microscopist to another.

Uncertainties have two main origins: a statistical one which is evaluated from the intensity of the spectrum itself and a more physical or experimental one which can be deduced from the dispersion of successive analyses. A complete estimation of the uncertainty should take into account the contribution of both types of errors. The fact that almost all participants, refer only to one type of error combined with very different numbers of analysis (2 to 30 ) mainly explains the high discrepancy of uncertainties observed in the test. A normalization of the uncertainty calculation procedure is highly needed.

\section{Test 1994: "EDXS Quantitative Analysis of Light Elements"}

3.1 TEST CONDITIONS AND RESUlTS - The 1994 test was focused on quantitative analysis of light elements. Only six laboratories being equipped with ultra-thin windows, the members of the others laboratories have participated to this experiment with them forming 6 groups.

The specimen provided to the participants is an ion milled thin foil prepared from a single crystal of $\mathrm{Fe} / \mathrm{Ni}$ oxide whose iron oxidation state $\left(\mathrm{Fe}^{3+} / \mathrm{Fe}^{3+}+\mathrm{Fe}^{2+}\right)=0.86$ [7]. The reference formula is determined by microprobe analysis:

$$
\left(\mathrm{Fe}_{2.26 \pm 0.005} \mathrm{Ni}_{0.66 \pm 0.005} \mathrm{Al}_{0.07 \pm 0.004}\right) \mathrm{O}_{4} \text {. }
$$

The value of the iron oxidation state is not communicated to the participants who are thus obliged to measure the oxygen content to fully determine the sample formula. 
As a consequence of the previous test, the six groups of participants have decided to use the parameterless Van Cappellen method. The results of $\mathrm{Fe}, \mathrm{Ni}, \mathrm{Al}$ atomic concentration determinations shown in Figure 3 bracket quite correctly the reference values. The mean value is $\mathrm{Fe}_{2.27 \pm 0.12} \mathrm{Ni}_{0.67 \pm 0.04} \mathrm{Al}_{0.065 \pm 0.010}$ and the dispersion of the results for $\mathrm{Fe}$ and $\mathrm{Ni}$ is better than $6 \%$.

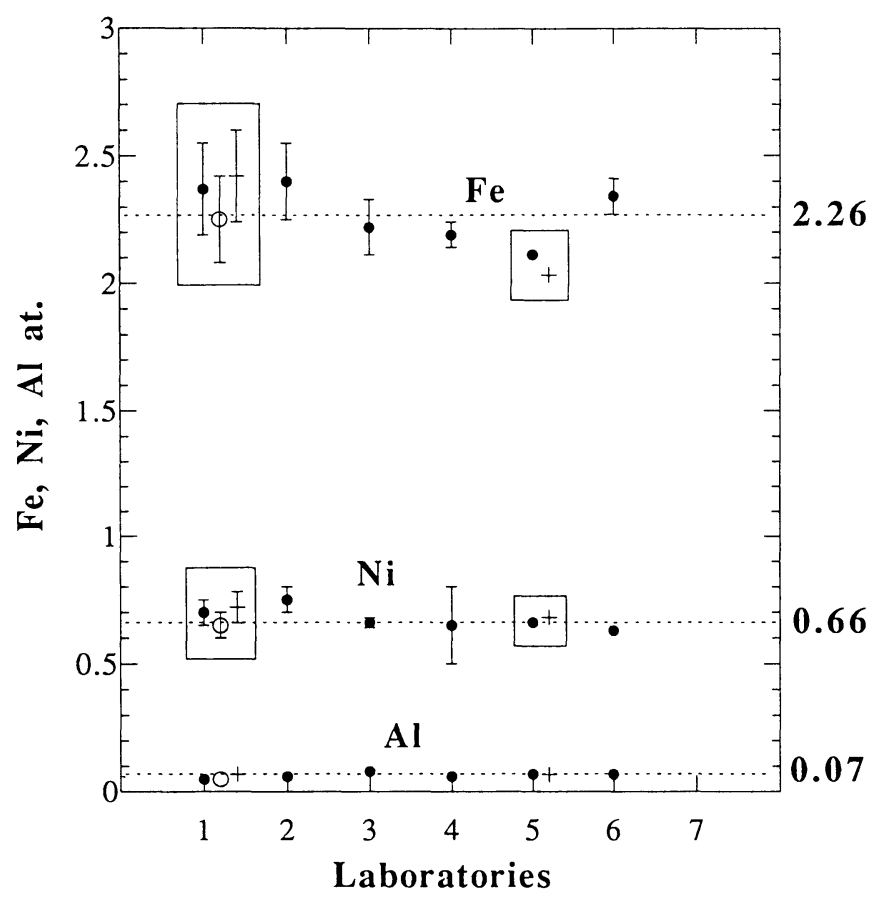

Fig. 3. - EDXS 1994 results: Atomic concentrations $\mathrm{Fe}, \mathrm{Ni}, \mathrm{Al}$ measured by each group of participants. Two groups (\# 1 and 5, data results in boxes) have used several absorption correction techniques: Van Cappellen method (filled circles), absorption correction with evaluation of thickness by mean of $\mathrm{Fe}_{\mathrm{K}} / \mathrm{Fe}_{\mathrm{L}}$ ratio (open circles) and by EELS (crosses).

3.2 ANALYSIS OF RESULTS, CRITICAL EVALUATION AND CONCLUDING REMARKS - In spite of the increased difficulty of the analysis, the dispersion of the results is reduced if compared to the 1993 test. We think that it is largely due to a general better knowledge of all factors responsible for a dispersion of data: thin film artifact, better utilization of Van Cappellen method and correct determination of $k$-factors.

3.2.1 From Oxygen Composition to Iron Oxidation State - The quality of the results is directly related to the quality of the calibration of $k$-factors especially the $k_{\mathrm{OFe}}$ which is used for the determination of the oxygen concentration.

This specimen provided the possibility to obtain an extra information on the sample composition which is the valence ratio of $\mathrm{Fe}^{2+}$ and $\mathrm{Fe}^{3+}$. Indeed, assuming the stoichiometry of the sample and charge balance of cations $\left(\mathrm{Fe}^{2+}, \mathrm{Fe}^{3+}, \mathrm{Ni}^{2+}, \mathrm{Al}^{3+}\right)$ by anions $\left(\mathrm{O}^{2-}\right)$, the oxygen atomic concentration can be expressed by the relation:

$$
2[\mathrm{O}]=2\left[\mathrm{Fe}^{2+}\right]+3\left[\mathrm{Fe}^{3+}\right]+2\left[\mathrm{Ni}^{2+}\right]+3\left[\mathrm{Al}^{3+}\right] \text {. }
$$


Table I shows that $\left(\mathrm{Fe}^{3+} / \mathrm{Fe}^{3+}+\mathrm{Fe}^{2+}\right)$ varies between $63 \%$ and $100 \%$ with an uncertainty of 10 to $20 \%$. These results are of relative good quality if we notice that such determination was considered as impossible a few years ago. It is also remarkable to underline that the quality of this determination, which is greatly dependent on the precision on the oxygen concentration, seems quite independent of the quality of the detector system i.e. transmission of ultra-thin window as can be seen from $k_{\mathrm{OFe}}$ values (Tab. I). This suggests that it is possible to increase the quality of these results.

Table I. - EDXS 1994 results, O/Fe $k$-factors and iron oxidation states.

\begin{tabular}{cccccc}
\hline $\mathrm{Lab}$ & $\mathrm{Fe}$ & $\mathrm{Ni}$ & $\mathrm{Al}$ & $\mathrm{kOFe}$ & $\frac{\mathrm{Fe}^{3+}}{\mathrm{Fe}^{3+}+\mathrm{Fe}^{2+}}$ \\
\hline 1 & $2.37 \pm 0.18$ & $0.70 \pm 0.05$ & $0.05 \pm 0.01$ & 8.33 & $\mathbf{7 2 \pm 1 0 \%}$ \\
2 & $2.40 \pm 0.15$ & $0.75 \pm 0.05$ & $0.06 \pm 0.01$ & 1.80 & $\mathbf{6 3} \pm 9 \%$ \\
3 & $2.22 \pm 0.11$ & $0.66 \pm 0.02$ & $0.08 \pm 0.01$ & 1.78 & $\mathbf{9 0 \pm 7 \%}$ \\
4 & $2.19 \pm 0.05$ & $0.65 \pm 0.15$ & $0.06 \pm 0.03$ & 3.78 & $\mathbf{9 8 \%}$ \\
5 & 2.11 & 0.66 & 0.07 & 1.20 & $>\mathbf{1 0 0 \%}$ \\
6 & $2.34 \pm 0.07$ & 0.63 & 0.07 & 7.80 & $\mathbf{7 9 \%}$ \\
\hline
\end{tabular}

3.2.2 Alternative Procedures for Absorption Correction - Two groups of participants tested two alternative methods (Fig. 3). The first one is an estimation of the sample thickness from EELS measurements in order to avoid the problem of intensity fluctuations in the Van Cappellen method (group \# 1 and 5). This method does not seem to give better results than the nominally Van Cappellen method. The second approach has used the $\mathrm{Fe}_{\mathrm{K}} / \mathrm{Fe}_{\mathrm{L}}$ intensity as an evaluation of thickness, in order to avoid tedious and rather doubtful thickness measurements necessary for classical absorption correction method (group \# 1). The result obtained with this last technique is notably better than others and, if not fortuitous, could be an interesting alternative method.

\section{Conclusions and Perspectives}

The general result of a round robin test is fruitfully expressed in term of results dispersion. This dispersion was $40 \%$ in 1992, $13 \%$ in 1993 and $6 \%$ in 1994 . The increasing convergence of results evidences the interest of such collective investigations. From a scientific point of view, this means that any of these francilian microscopists should be able to give a quantitative measurement of composition with a reliability and accuracy better than $10 \%$, if the correct and rigorous experimental procedure is undertaken.

The analysis of an homogeneous specimen does not require very peculiar instrumentation but involves the know-how of the microscopist. From this point of view, special attention has been given to:

- various specimen tricks;

- errors evaluation procedure; 
- absorption correction procedure.

The next tests will deal with analysis of microheterogeneities.

\section{Acknowledgements}

P. Veyssière and J. Ingrin have kindly provided the materials used for these tests. M. Rommeluere and C. Bahezreto have provided access to the microprobe of CNRS- Meudon. We thank M. Beck, Director of the CNRS-PIRMAT, for the financial support of the "Chemical Analysis" workshop.

\section{References}

[1] Bouchet D. and the "Réseau Francilien de Microscopie Electronique en Transmission", Microsc. Microanal. Microstruct. 4 (1993) 387-399.

[2] Takei H., J. Crystal Growth 43 (1978) 463.

[3] Van Cappellen E., Microsc. Microanal. Microstruct. 1 (1990) 1.

[4] Doig P. and Flewitt P.E.J., J. Microsc. 110 (1977) 107.

[5] Foitzik A.H., Xiao S.Q. and Heuer A.H., Ultramicrosc. 50 (1993) 229.

[6] Williams D.B., Practical analytical electron microscopy in materials science (Philips Electron Instr. Inc.) N.J. (1984) p. 153.

[7] Veyssière P., Ph. D., University of Poitiers (1977) p.187. 